Bull. Mater. Sci., Vol. 36, No. 4, August 2013, pp. 629-634. (C) Indian Academy of Sciences.

\title{
Effect of plasticizer and fumed silica on ionic conductivity behaviour of proton conducting polymer electrolytes containing $\mathbf{H P F}_{6}$
}

\author{
JITENDER PAUL SHARMA* and S S SEKHON ${ }^{\dagger}$ \\ Department of Physics, Doaba College, Jalandhar, India \\ ${ }^{\dagger}$ Department of Physics, Guru Nanak Dev University, Amritsar 143 005, India
}

\begin{abstract}
The effect of addition of propylene carbonate (PC) and nano-sized fumed silica on the ionic conductivity behaviour of proton conducting polymer electrolytes containing different concentrations of hexafluorophosphoric acid $\left(\mathrm{HPF}_{6}\right)$ in polyethylene oxide (PEO) has been studied. The addition of PC results in an increase in ionic conductivity, whereas the addition of nano-sized fumed silica improves mechanical strength of electrolytes along with a small increase in ionic conductivity. It was observed that the simultaneous addition of PC and fumed silica results in electrolytes with optimum value of ionic conductivity and other properties.
\end{abstract}

Keywords. Polymer electrolytes; ionic conductivity; polyethylene oxide; plasticizer; fumed silica.

\section{Introduction}

Since the pioneering work of Wright et al (1973) and Armand et al (1978), solid polymer electrolytes containing lithium salts have been widely studied (Armand 1987; Gray 1991; Scrosati 1993; Morita et al 1998). Proton conducting polymer electrolytes containing various inorganic acids and ammonium salts have also been studied (Armand et al 1990; Lassegues 1992; Chandra et al 2000; Kumar and Sekhon 2002; Sekhon et al 2007). Study of polymer electrolytes based on different polymers such as poly(ethylene oxide) (PEO), poly (methylmethacrylate) (PMMA), poly(vinylidene fluoride) (PVdF), poly(vinyl chloride) (PVC) and poly(acrylonitrile) (PAN), etc has been the subject of great interest in recent years due to their potential applications in rechargeable batteries, fuel cells, sensors, supercapacitors, electrochromic display devices, etc (Armand et al 1979; Weston and Steele 1982; Owen 1989; Scrosati 1993; Gray 1997). Amongst these polymers, PEO can dissolve high concentrations of a wide variety of dopants (Armand et al 1979). However, due to the large crystallinity, high ionic conductivity at room temperature has not been achieved (Armand et al 1979; Quartarone et al 1998). At present, special interest has been focused on the development of polymer electrolytes having high ionic conductivity at ambient temperature because of their practical applications. Amorphous phase has been generally reported to be the high conducting phase in these polymer electrolytes (Berthier et al 1983). To enhance ionic conductivity, various approaches such as using salts with large anions, polymer blends, plasticizers, composite materials, etc have been used in different polymer electrolytes (Cowie 1987; Armand et al 1990; Gray 1991; Abraham 1993; Croce et al 1998; Appetecchi et al 2000;

\footnotetext{
*Author for correspondence (sharma_jp78@yahoo.co.in)
}

Forsyth et al 2002; Kumar and Sekhon 2002; Kumar 2004; Sekhon et al 2007; Pradhan et al 2009). Enhancement in ionic conductivity by about two orders of magnitude has been observed for plasticized polymer electrolytes. The addition of high dielectric constant plasticizer dissociates some ion aggregates into free ions which lead to an enhancement in ionic conductivity. However, the addition of large concentration of plasticizer leads to poor mechanical strength of plasticized polymer electrolytes. The composite polymer electrolytes obtained by adding insulating matrix to polymer electrolytes have been proposed by Weston and Steele (1982). However, the ionic conductivity of composite polymer electrolytes is not large enough as required for practical applications. An improvement in mechanical properties of different nanocomposite polymer electrolytes has also been observed by different workers (Pitawala et al 2008; Sharma and Sekhon 2009; Ramesh et al 2010). Therefore, the development of polymer electrolytes with high ionic conductivity and good mechanical strength will be required for their use in different applications.

In the present work, the effect of simultaneous addition of both plasticizer and insulating matrix on the properties of PEO-based polymer electrolytes containing hexafluorophosphoric acid $\left(\mathrm{HPF}_{6}\right)$ has been studied.

\section{Experimental}

Polyethylene oxide (PEO) (Aldrich, av. mol. wt $5 \times 10^{6}$ ), hexafluorophosphoric acid $\left(\mathrm{HPF}_{6}\right)$ (Aldrich), propylene carbonate (PC) (Merck) and fumed silica (Aldrich) with an average particle size, $7 \mathrm{~nm}$, have been used as the starting materials. Polymer electrolytes have been prepared by the solution casting method using methanol as solvent. PEO, $\mathrm{HPF}_{6}$ and $\mathrm{PC}$ taken in stoichiometric ratio, were dissolved 
in methanol and stirred for 8-10 h to obtain a clear solution. Subsequently, nano-sized fumed silica was incorporated/ dispersed into a polymer matrix under vigorous stirring to form nanocomposite polymer electrolytes. Obtained viscous solution was then poured into polypropylene dishes kept under dry atmosphere and the solvent was allowed to evaporate slowly. Free standing films of polymer electrolytes so obtained were dried under vacuum at $45^{\circ} \mathrm{C}$ for $24 \mathrm{~h}$. Films of PEO:HPF 6 polymer electrolytes having compositions in weight percent, viz. (100:0), (95:5) and (90:10), etc were prepared by solution casting method. Films of plasticized and plasticized-nanocomposite polymer electrolytes were prepared by adding $y \mathrm{wt} \% \mathrm{PC}$ and $(y+z) \mathrm{wt} \%$ (PC and fumed silica concentration) of total weight (90 PEO-10 $\mathrm{HPF}_{6}+$ $y \mathrm{PC}+z$ fumed silica). The ionic conductivity of polymer electrolytes was measured by complex impedance spectroscopy using computer interfaced Hioki 3532-50 LCR HiTester in $40 \mathrm{~Hz}-5 \mathrm{MHz}$ frequency range. The conductivity was also measured at different temperatures in $25-100{ }^{\circ} \mathrm{C}$ temperature range by keeping the sample holder containing polymer electrolyte in a temperature controlled furnace. FTIR spectra of different polymer electrolytes were recorded with computer interfaced Shimadzu 8400S FTIR spectrometer at room temperature in $400-4000 \mathrm{~cm}^{-1}$ wavenumber range. Crystalline/amorphous nature of different polymer electrolytes was studied by $\mathrm{X}$-ray diffraction using Philips analytic X-ray diffractometer (by using copper as a source of $\mathrm{K}_{\alpha}$ radiation having a wavelength of $1.5415 \AA$ ). Thermal properties of different polymer electrolytes were studied by DSC/TGA with Perkin Elmer Pyris Diamond system in different temperature ranges at a heating rate of $10{ }^{\circ} \mathrm{C} / \mathrm{min}$ under nitrogen atmosphere. Morphology of different polymer electrolytes was studied by Hitachi S-4700 scanning electron microscope at an accelerating voltage of $10 \mathrm{kV}$.

\section{Results and discussion}

\subsection{Conductivity}

3.1a Conductivity vs acid concentration: The ionic conductivity of polymer electrolytes having composition, PEO$x$ (wt $\%) \mathrm{HPF}_{6}$, was measured at different concentrations of $\mathrm{HPF}_{6}$ and conductivity of PEO $\left(\sim 10^{-9} \mathrm{~S} / \mathrm{cm}\right)$ has been observed to increase by three orders of magnitude $\left(\sim 10^{-6} \mathrm{~S} / \mathrm{cm}\right)$ with the addition of $\mathrm{HPF}_{6}$. Maximum ionic conductivity of $8.8 \times 10^{-6} \mathrm{~S} / \mathrm{cm}$ is obtained at $25^{\circ} \mathrm{C}$ for electrolytes containing $10 \mathrm{wt} \% \mathrm{HPF}_{6}$ (figure 1). Initially, with an increase in $\mathrm{HPF}_{6}$ concentration, free charge carrier concentration increases which results in an increase in conductivity, as also observed by Srivastava et al (1995) for $\mathrm{PEO}-\mathrm{NH}_{4} \mathrm{SCN}$ system. However, at higher acid concentrations, the conductivity does not increase at the same rate, which may be explained to be due to the formation of neutral ion aggregates. Figure 1 also shows variation of ionic conductivity of polymer electrolytes having composi-

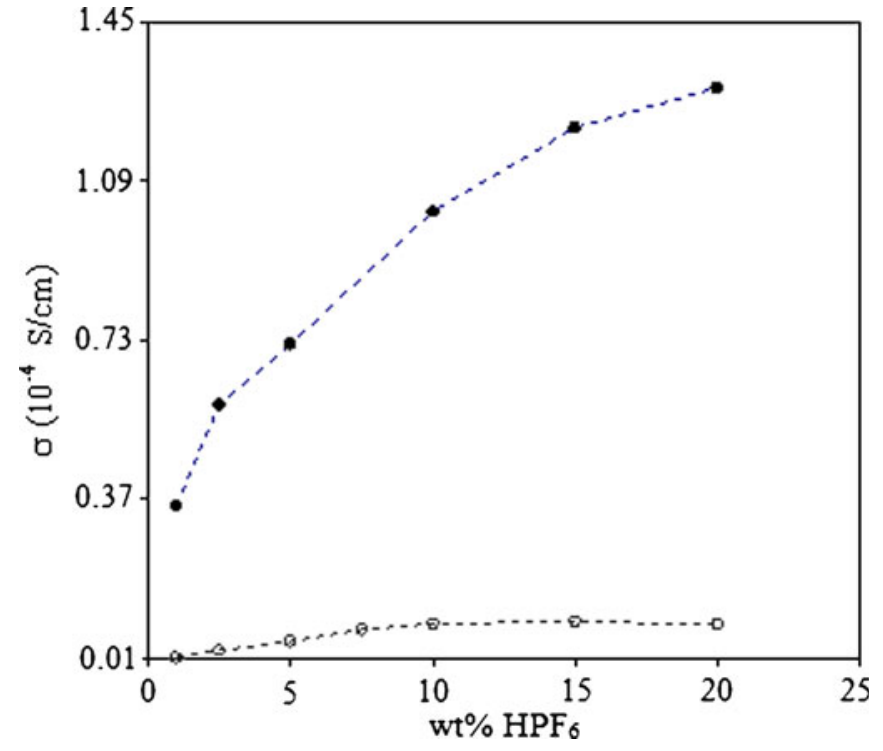

Figure 1. Variation of conductivity with $\mathrm{HPF}_{6}$ concentration for polymer electrolytes having composition $\mathrm{PEO}-x \mathrm{wt} \% \mathrm{HPF}_{6}(\mathbf{a})$ and PEO-32 wt\% PC- $x$ wt\% $\mathrm{HPF}_{6}$ (b).

tion, $\mathrm{PEO}-32 \mathrm{wt} \% \mathrm{PC}-x \mathrm{wt} \% \mathrm{HPF}_{6} \mathrm{vs}_{\mathrm{HPF}}$ concentration. An enhancement in ionic conductivity by two orders of magnitude $\left(\sim 10^{-4}\right)$ has been observed with an increase in $\mathrm{HPF}_{6}$ concentration, reaching maximum ionic conductivity of $1.02 \times 10^{-4} \mathrm{~S} / \mathrm{cm}$ at $10 \mathrm{wt} \% \mathrm{HPF}_{6}$. From figure 1 , it has been observed that plasticized polymer electrolytes containing $\mathrm{PC}$ have higher ionic conductivity than unplasticized $\left(\mathrm{PEO}-\mathrm{HPF}_{6}\right)$ polymer electrolytes at all concentrations of $\mathrm{HPF}_{6}$. The higher ionic conductivity of plasticized polymer electrolytes is generally due to the higher dielectric constant and plasticizing nature of PC. The increase in ionic conductivity of different polymer electrolytes containing plasticizers is also related to an increase in the amorphous phase, which is reported to be the high conducting phase in polymer electrolytes (Berthier et al 1983).

Figure 2 shows variation of ionic conductivity of 90 PEO:10 $\mathrm{HPF}_{6}$ and 90 PEO:10 $\mathrm{HPF}_{6}-32 \mathrm{wt} \% \mathrm{PC}$ as a function of fumed silica concentration. Increase in ionic conductivity for ( $\mathrm{PEO}-\mathrm{HPF}_{6}$-fumed silica) nanocomposite polymer electrolytes has been observed by a small amount as compared to (PEO- $\mathrm{HPF}_{6}-\mathrm{PC}$-fumed silica) plasticizednanocomposite polymer electrolytes (figure 2 ). On the other hand, ionic conductivity at higher concentrations of fumed silica decreases because excessive dispersion of fumed silica particles impedes the movement of ions. Maximum ionic conductivities of $1.93 \times 10^{-5}$ and $6.89 \times 10^{-4} \mathrm{~S} / \mathrm{cm}$ at room temperature have been observed for nanocomposite polymer electrolytes containing $4 \mathrm{wt} \%$ fumed silica and both $32 \mathrm{wt} \%$ $\mathrm{PC}$ as well as $4 \mathrm{wt} \%$ fumed silica, respectively. An improvement in the mechanical properties of nanocomposite polymer electrolytes has also been observed visually.

3.1b Conductivity vs temperature: Dependence of ionic conductivity on temperature in the range of $25-125^{\circ} \mathrm{C}$ for 


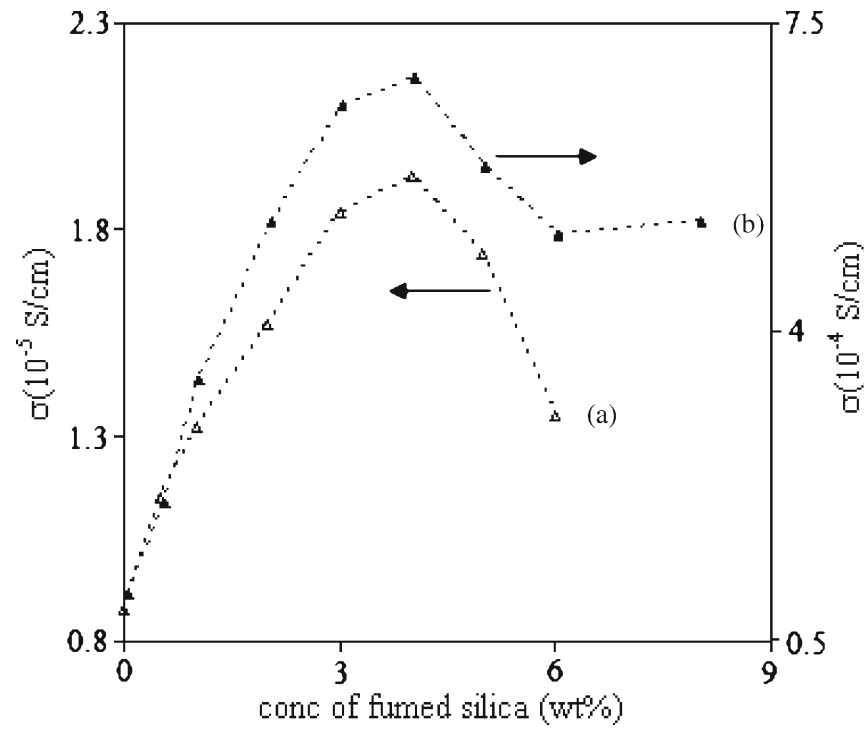

Figure 2. Variation of conductivity with fumed silica concentration for polymer electrolytes having composition $90 \mathrm{PEO}^{10 \mathrm{HPF}_{6}-}$ $z$ wt $\%$ fumed silica (a) and 90 PEO: $10 \mathrm{HPF}_{6}-32 \mathrm{wt} \% \mathrm{PC}-z, \mathrm{wt} \%$ fumed silica (b).

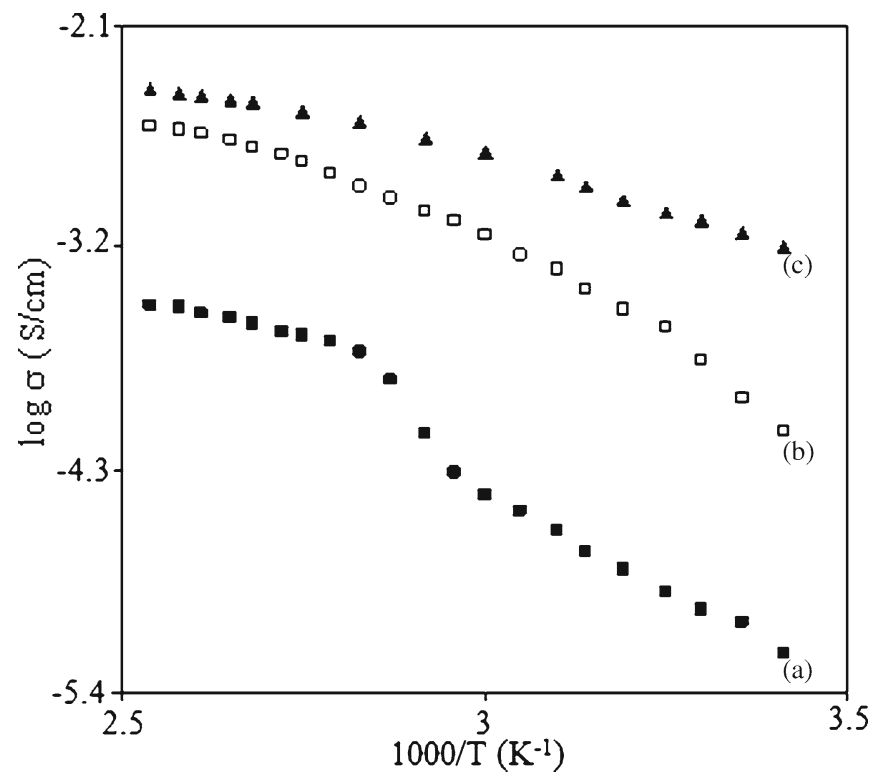

Figure 3. Variation of $\log$ conductivity with reciprocal tempera-

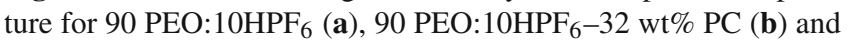
90 PEO: $10 \mathrm{HPF}_{6}-32 \mathrm{wt} \%$ PC-4 wt $\%$ fumed silica (c).

different polymer electrolytes has been studied and the variation is shown in figure 3. Sharp increase in the ionic conductivity of $\mathrm{PEO}-\mathrm{HPF}_{6}$ at about $65^{\circ} \mathrm{C}$ corresponds to the semicrystalline to amorphous phase transition of PEO (Papke et al 1981). For polymer electrolytes containing PC and fumed silica, almost a linear variation in ionic conductivity as a function of temperature has been observed, which shows Arrhenius type thermally-activated behaviour (table 1). Activation energies have been calculated for ion transport below
Table 1. Thermal data for different polymer electrolytes.

\begin{tabular}{|c|c|c|c|}
\hline Sample (electrolyte system) & $T_{\mathrm{m}}\left({ }^{\circ} \mathrm{C}\right)$ & $\Delta H_{\mathrm{m}}\left(\mathrm{Jg}^{-1}\right)$ & $\chi_{\mathrm{c}}(\%)$ \\
\hline PEO & 74 & $209 \cdot 0$ & 100 \\
\hline 90 PEO:10 $\mathrm{HPF}_{6}$ & 72 & $107 \cdot 0$ & 51 \\
\hline 90 PEO: $10 \mathrm{HPF}_{6}-32 \mathrm{wt} \%$ PC & 69 & $96 \cdot 8$ & 46 \\
\hline $\begin{array}{l}90 \text { PEO: } 10 \mathrm{HPF}_{6}-32 \mathrm{wt} \% \\
\text { PC-4 wt } \% \text { fumed silica }\end{array}$ & 64 & 89.6 & 42 \\
\hline
\end{tabular}

and above the melting temperature and are presented in table 2. Decrease in activation energy (from 0.194 to 0.085 \pm $0.002 \mathrm{eV}$ ) for the polymer electrolytes containing PC and fumed silica implies a decrease of the energy barrier to ion transport which in turn facilitates fast ion movement in polymer electrolytes. From the above results, it is revealed that plasticized-nanocomposite polymer electrolytes have higher ionic conductivity and smaller activation energy as compared to other electrolytes.

\subsection{FTIR studies}

The complexation of PEO with $\mathrm{HPF}_{6}$, presence of free ions, ion aggregates and their dissociation with the addition of $\mathrm{PC}$ have been observed by FTIR and spectra of some samples in the selected region is shown in figure 4. Peaks at 560, 730 and $820 \mathrm{~cm}^{-1}$ are assigned to the presence of free $\mathrm{PF}_{6}^{-}$ anions. The shoulder at $860 \mathrm{~cm}^{-1}$ is attributed to the presence of ion aggregates. Peaks in the region $850-1450 \mathrm{~cm}^{-1}$ corresponds to $-\mathrm{C}-\mathrm{O}-\mathrm{C}-$ stretching and deformation mode. Some important peaks related to PEO and PC have also been assigned by our group previously (Sharma and Sekhon 2006a, b). Peaks at about 1020,1080 and $1150 \mathrm{~cm}^{-1}$ related to $-\mathrm{C}-\mathrm{O}-\mathrm{C}-$ symmetric and asymmetric stretching vibrations and doublet at 1343 and $1360 \mathrm{~cm}^{-1}$ related to swinging vibrations of $\mathrm{CH}_{2}$ group are characteristics of crystalline PEO phase (Li and Hsu 1984). With the addition of $\mathrm{HPF}_{6}$ to PEO, some new peaks along with a shift in the position of existing peaks of PEO confirms the polymer-salt complexation. With the addition of PC in polymer electrolytes, shoulder at $860 \mathrm{~cm}^{-1}$ disappears due to the dissociation of ion aggregates. These FTIR results are in agreement with the ionic conductivity results (figure 1) as the dissociation of ion aggregates with the addition of PC enhances the free ion concentrations and hence ionic conductivity. With the addition of $\mathrm{PC}$ and fumed silica, changes in the frequencies of $-\mathrm{C}-\mathrm{O}-\mathrm{C}-$ vibrations of $\mathrm{PEO}$ may be due to the weakening of interaction between ether oxygen of PEO and $\mathrm{HPF}_{6}$ and an increase in PEO flexibility which leads to further increase in ionic conductivity. It is also observed from FTIR spectra that peaks at around $1000-1150 \mathrm{~cm}^{-1}$ corresponding to the crystalline PEO phase disappeared and doublet (at 1343 and $1360 \mathrm{~cm}^{-1}$ ) changes to a single sharp band at around $1350 \mathrm{~cm}^{-1}$ (due to swinging vibration of $\mathrm{C}-\mathrm{H}$ in $\mathrm{CH}_{2}$ in amorphous phase of PEO). 


\section{$3.3 X R D$ studies}

Figure 5 shows X-ray diffraction patterns for different polymer electrolytes. Addition of plasticizer PC to $\mathrm{PEO}-\mathrm{HPF}_{6}$ has been observed to result in an increase in the amorphous content. Diffractogram of PEO shows main characteristic peaks at $2 \theta=19$ and $23^{\circ}$. With the addition of $\mathrm{HPF}_{6}$ in PEO, new characteristic peaks are also observed at $2 \theta=42$, $43 \cdot 5,49,51$ and $72^{\circ}$, which are due to the presence of $\mathrm{HPF}_{6}$ and $\mathrm{PEO}-\mathrm{HPF}_{6} \mathrm{Complex}$ formation. Peaks corresponding to $\mathrm{HPF}_{6}$ (spectra not shown) and PEO-HPF 6 disappear with the addition of PC and fumed silica. The decrease in the intensity and significant broadening in PEO peaks at $2 \theta=19$ and $23^{\circ}$ indicates a decrease in the crystallinity with the addition of PC and fumed silica. These results are in agreement with the ionic conductivity results.

\subsection{DSC/TGA studies}

DSC/TGA thermograms were recorded for different polymer electrolytes to study the effect of $\mathrm{HPF}_{6}, \mathrm{PC}$ and fumed silica upon crystallinity (\%) of PEO and thermal stability. For PEO, endothermic peak at $74^{\circ} \mathrm{C}$ corresponds to the melting point $\left(T_{\mathrm{m}}\right)$ of $\mathrm{PEO}$ as shown in figure 6. A decrease in the melting temperature of PEO- $\mathrm{HPF}_{6}\left(T_{\mathrm{m}}=72^{\circ} \mathrm{C}\right)$ and PEO- $-\mathrm{HPF}_{6}$ containing PC and fumed silica $\left(T_{\mathrm{m}}=64-69^{\circ} \mathrm{C}\right)$ has been observed indicating a decrease in crystallinity. This is due to the interaction between polymer and fumed silica particles which reduces the amount of crystalline phase of polymer into amorphous phase to some extent and hence enhancing the ionic conductivity (Choi and Shin 1997). The values of enthalpy of melting $\left(\Delta H_{\mathrm{m}}\right)$ and \% crystallinity $\left(\% \chi_{\mathrm{c}}\right)$ have been calculated assuming PEO to be $100 \%$

Table 2. Activation energies for different polymer electrolytes.

\begin{tabular}{lccc}
\hline & \multicolumn{2}{c}{ Activation energies (eV) } & \\
\cline { 2 - 3 } Sample (electrolyte system) & $\begin{array}{c}\text { Region I } \\
T<T_{\mathrm{m}}\end{array}$ & $\begin{array}{c}\text { Region II } \\
T<T_{\mathrm{m}}\end{array}$ & $\sigma(\mathrm{S} / \mathrm{cm})$ at $25{ }^{\circ} \mathrm{C}$ \\
\hline 90 PEO: $10 \mathrm{HPF}_{6}$ & $0.194 \pm 0.002$ & $0.116 \pm 0.002$ & $8.80 \times 10^{-6}$ \\
90 PEO: $10 \mathrm{HPF}_{6}-32 \mathrm{wt} \% \mathrm{PC}$ & $0.143 \pm 0.002$ & $1.02 \times 10^{-4}$ \\
90 PEO: $10 \mathrm{HPF}_{6}-32 \mathrm{wt} \%$ & $0.085 \pm 0.002$ & $6.89 \times 10^{-4}$ \\
PC-4\% fumed silica & & \\
\hline
\end{tabular}

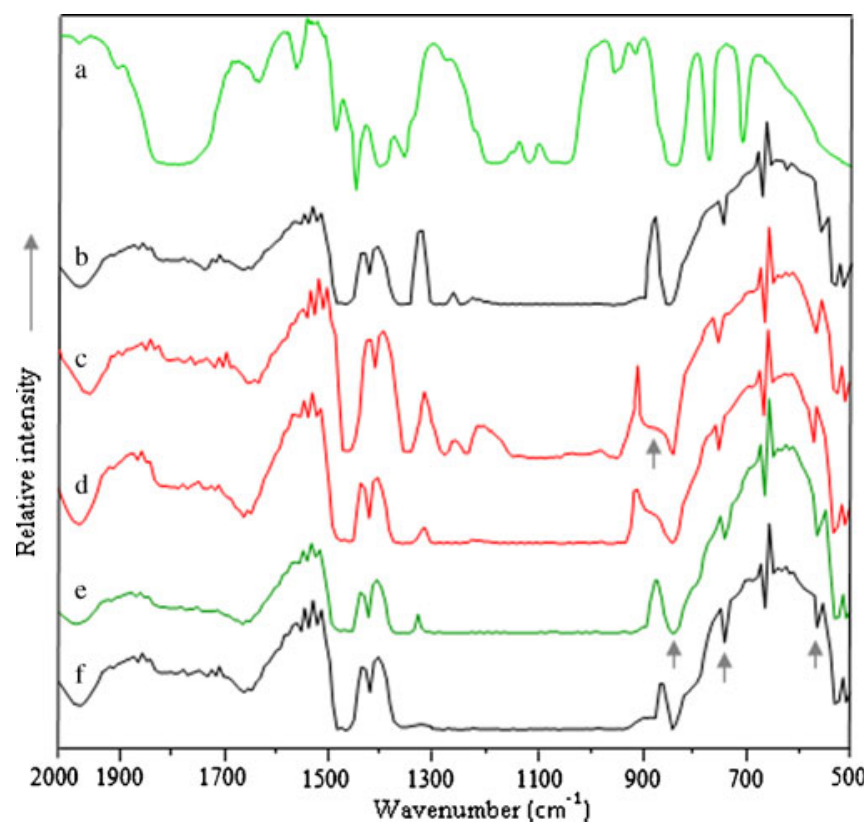

Figure 4. FTIR spectra of PEO (a), PEO containing $5 \mathrm{wt} \%$ (b), $10 \mathrm{wt} \%$ (c), $\mathrm{HPF}_{6}, 90 \mathrm{PEO}: 10 \mathrm{HPF}_{6}$ containing $19 \mathrm{wt} \%$ (d), $32 \mathrm{wt} \%$ (e) and PC and 90 PEO: $10 \mathrm{HPF}_{6}-32 \mathrm{wt} \% \mathrm{PC}$ containing $4 \mathrm{wt} \%$ fumed silica (f) in $500-2000 \mathrm{~cm}^{-1}$ region.

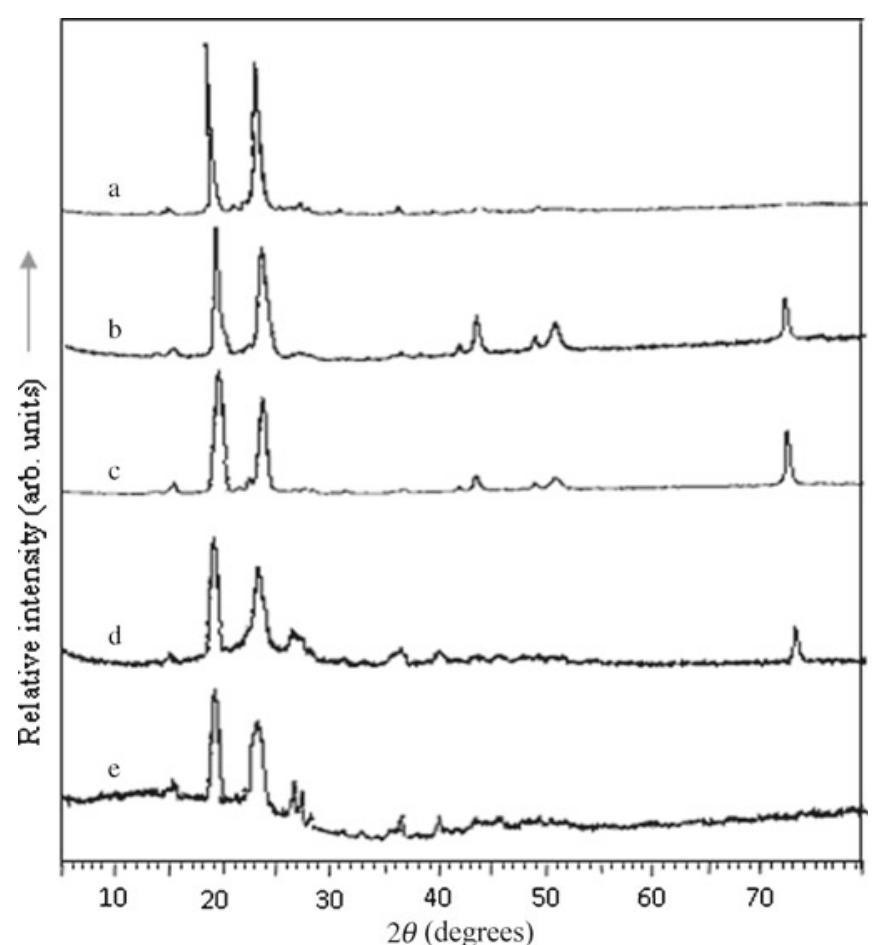

Figure 5. XRD pattern of $\mathrm{PEO}$ (a), $90 \mathrm{PEO}: 10 \mathrm{HPF}_{6}$ (b), 90 PEO: $10 \mathrm{HPF}_{6}-19 \mathrm{wt} \%$ PC (c), 90 PEO: $10 \mathrm{HPF}_{6}-32 \mathrm{wt} \%$ PC (d) and 90 PEO:10HPF $6-32 \mathrm{wt} \% \mathrm{PC}-4 \mathrm{wt} \%$ fumed silica (e). 
crystalline and results are listed in table 1 for different polymer electrolytes. The decrease in the value of $\Delta H_{\mathrm{m}}$ and $\% \chi_{\mathrm{c}}$ with the addition of fumed silica particles indicates increase in volume fraction of amorphous phase (Croce et al 1998; Scrosati et al 2000). TGA curve (figure 7) indicates no weight loss up to $200{ }^{\circ} \mathrm{C}$ and a gradual weight loss has

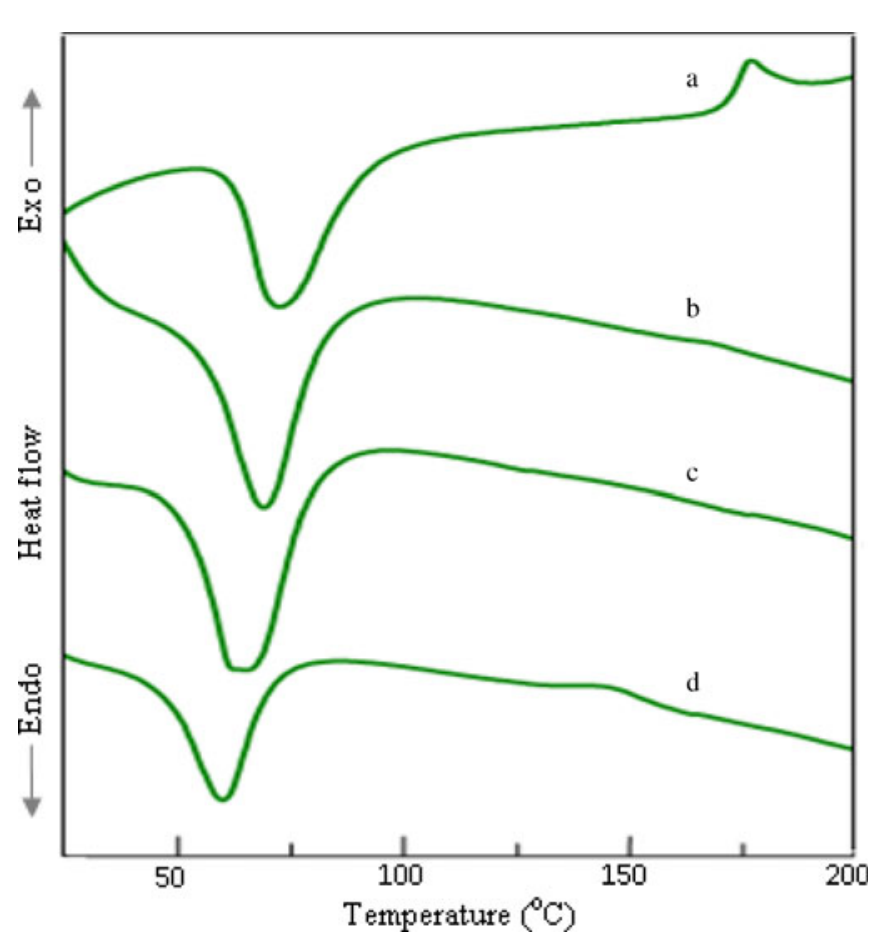

Figure 6. DSC plots for PEO (a), 90 PEO: $10 \mathrm{HPF}_{6}$ (b), 90 PEO: $10 \mathrm{HPF}_{6}-32 \mathrm{wt} \% \mathrm{PC}(\mathbf{c})$ and 90 PEO: $10 \mathrm{HPF}_{6}-32 \mathrm{wt} \%$ PC- $4 \mathrm{wt} \%$ fumed silica (d).

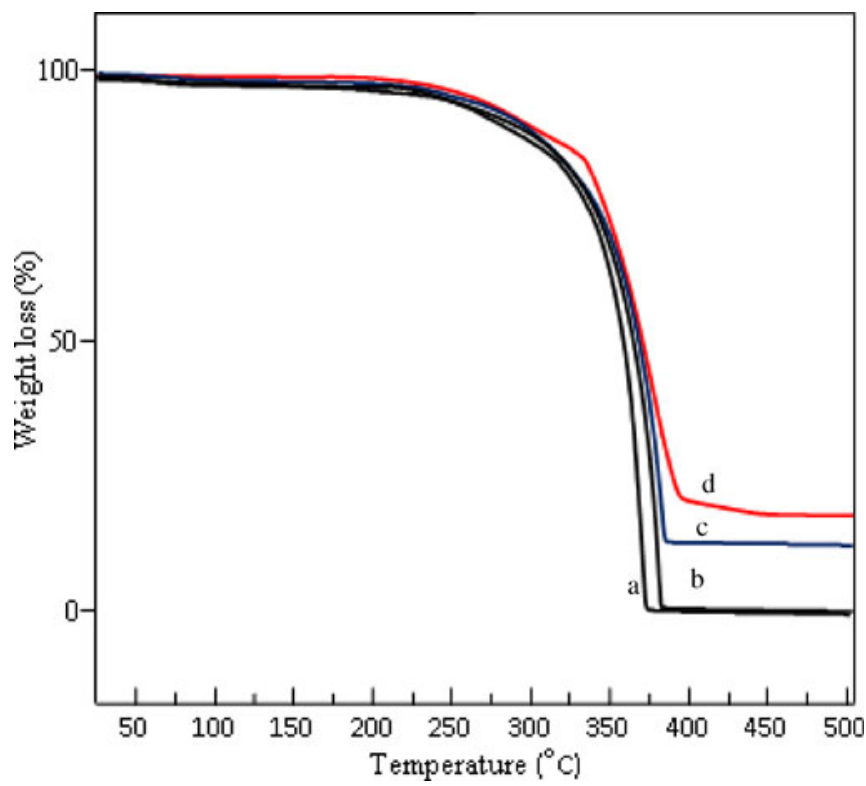

Figure 7. TGA plots for $\mathrm{PEO}$ (a), 90 PEO: $10 \mathrm{HPF}_{6}$ (b), 90 PEO: $10 \mathrm{HPF}_{6}-32 \mathrm{wt} \% \mathrm{PC}$ (c) and 90 PEO: $10 \mathrm{HPF}_{6}-32 \mathrm{wt} \%$ PC$4 \mathrm{wt} \%$ fumed silica $(\mathbf{d})$. been observed up to $300{ }^{\circ} \mathrm{C}$. Above this temperature, there is a rapid weight loss which could be due to the degradation of polymer electrolytes. Higher thermal stability has been observed for polymer electrolytes containing both PC and fumed silica as shown in figure 7 .

\subsection{SEM}

SEM photographs of different polymer electrolytes are shown in figure 8. Presence of spherulites in $\mathrm{PEO}-\mathrm{HPF}_{6}$ is
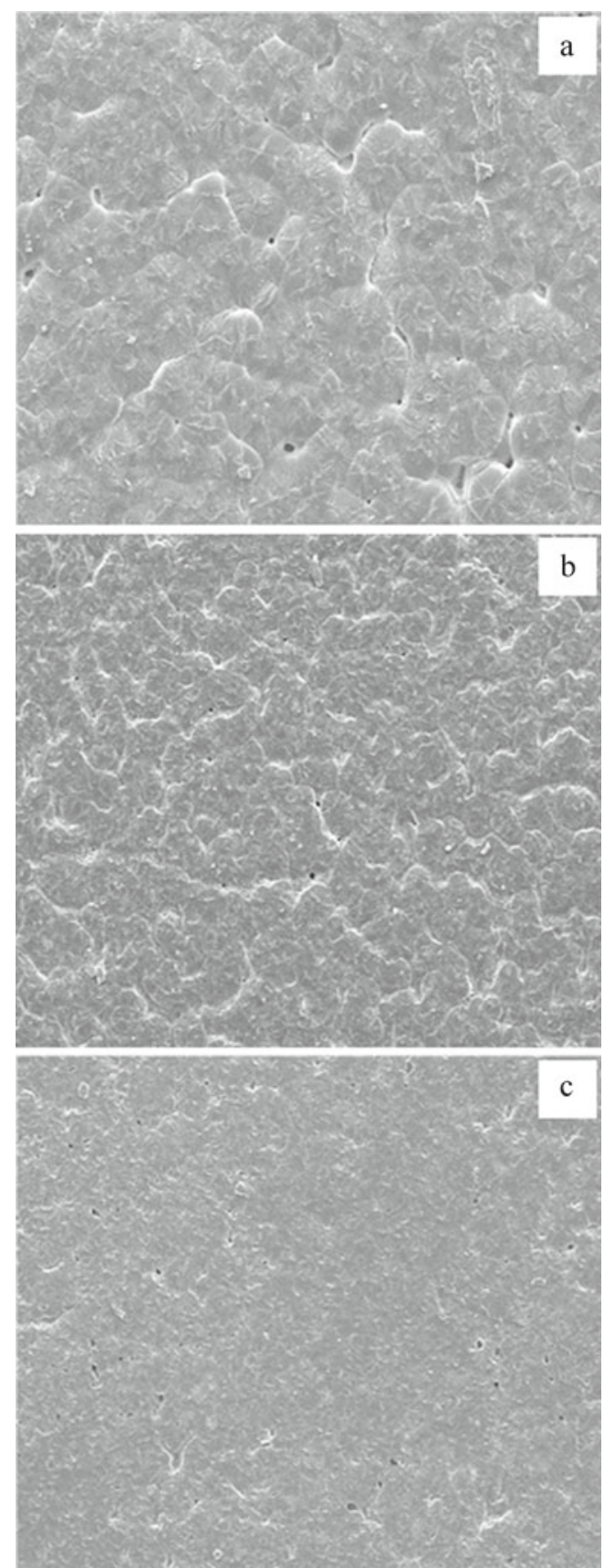

Figure 8. SEM photographs of 90 PEO:10HPF 6 (a), 90 PEO: $10 \mathrm{HPF}_{6}-32 \mathrm{wt} \%$ PC (b) and 90 PEO: $10 \mathrm{HPF}_{6}-32 \mathrm{wt} \%$ PC$4 \mathrm{wt} \%$ fumed silica (c). 
due to the existence of crystalline domains. Dark boundaries observed between spherulites show presence of partial amorphous phase. Improvement of surface morphology from rough to smooth surface is observed for polymer electrolytes containing PC and fumed silica. The appearance of pores due to entrapping of PC and fumed silica particles in polymer electrolytes is related to the reduction in crystallinity which leads to an enhancement in the amorphous content and hence ionic conductivity.

\section{Conclusions}

Ionic conductivity of PEO-based polymer electrolytes has been enhanced with the incorporation of $\mathrm{PC}$ and fumed silica. Highest ionic conductivity of $6.89 \times 10^{-4} \mathrm{~S} / \mathrm{cm}$ and lowest activation energy of $0.085 \pm 0.002 \mathrm{eV}$ has been obtained for polymer electrolytes containing both $\mathrm{PC}$ as well as fumed silica (plasticized-nanocomposite polymer electrolytes). FTIR results reveal polymer-salt complexation, presence of ion aggregates and their dissociation with the addition of PC. XRD and DSC results indicate that the amorphous content of polymer electrolytes increases with the addition of PC. Visual observations and TGA plots suggest that mechanical strength as well as thermal stability of plasticizednanocomposite polymer electrolytes remain fairly high along with high value of ionic conductivity. Smooth surface morphology observed from SEM photographs for polymer electrolytes containing PC indicates a decrease in the crystallite size which results in an increase in the amorphous content of polymer electrolytes and hence ionic conductivity.

\section{References}

Abraham K M 1993 in Applications of electroactive polymers (ed.) B Scrosati (London: Chapman \& Hall) p. 75

Appetecchi G B, Croce F, Persi L, Ronci F and Scrosati B 2000 Electrochim. Acta 451481

Armand M B 1987 in Polymer electrolyte reviews (eds) J R MacCallum and C A Vincent (London: Elsevier Applied Science) Vol. I, p. 7

Armand M B, Chabagno J M and Duclot M 1978 in Second international meeting on solid electrolytes (Scotland: Extended Abstracts)

Armand M B, Chabagno J M and Duclot M 1979 in Fast on transport in solids (eds) P Vashista et al (New York: Elsevier) p. 131
Armand M, Gorecki W and Andreani R 1990 in Second international symposium on polymer electrolytes (ed.) B Scrosati (London: Elsevier Applied Science) p. 91

Berthier C, Gorecki W, Minier M, Armand M B, Chabagno J M and Rigaud P 1983 Solid State Ionics 1191

Chandra S, Sekhon S S and Arora N 2000 Ionics 6112

Choi B K and Shin K H 1997 J. Appl. Electrochem. 27365

Cowie J M G 1987 in Polymer electrolyte reviews (eds) J R MacCallum and C A Vincent (London: Elsevier Applied Science) Ch. 4, Vol. 1

Croce F, Appetecchi G B, Persi L and Scrosati B 1998 Nature 394 456

Forsyth M, MacFarlane D R, Best A, Adebahr J and Hill A J 2002 Solid State Ionics 147203

Gray F M 1991 in Solid polymer electrolytes: Fundamentals and technological applications (New York: VCH Publishers Inc.)

Gray F M 1997 in Polymer electrolytes (Cambridge: RSC Materials Monographs, The Royal Society of Chemistry)

Kumar B 2004 J. Power Sources 135215

Kumar M and Sekhon S S 2002 Eur. Polym. J. 381297

Lassegues J C 1992 in Proton conductors: Solids, membranes and gels-materials and devices (ed.) P Colomban (Cambridge: Cambridge University Press) p. 311

Li X and Hsu S L 1984 J. Polym. Sci.: Polym. Phys. 221331

Morita M, Ishikawa M and Matsuda Y 1998 in Lithium polymer batteries (eds) M Wakihara and O Yamamoto (Weinheim: Wiley $\mathrm{VCH})$ ch. 7

Owen J R 1989 in Superionic solids and solid electrolytes-recent trends (eds) A L Laskar and S Chandra (New York: Academic Press) p. 111

Papke B L, Ratner M A and Shriver D F 1981 J. Phys. Chem. Solids 42493

Pitawala H M J C, Dissanayake M A K L, Seneviratne V A, Mellander B E and Albinson I 2008 J. Solid State Electrochem. 12783

Pradhan D K, Choudhary R P N and Samantaray B K 2009 Mat. Chem. Phys. 115557

Quartarone E, Mustarelli P and Magistris A 1998 Solid State Ionics 1101

Ramesh S, Winie T and Arof A K 2010 J. Mater. Sci. 451280

Scrosati B 1993 in Applications of electroactive polymers (London: Chapman and Hall)

Scrosati B, Croce F and Persi L 2000 J. Electrochem. Soc. 51718

Sekhon S S, Sharma J P and Park J S 2007 Macromol. Symp. 249-250 209

Sharma J P and Sekhon S S 2006a J. Mater. Sci. 413617

Sharma J P and Sekhon S S 2006b Phys. Status Solidi (a) 2032037

Sharma J P and Sekhon S S 2009 J. Sci. Conf. Proc. 118

Srivastava N, Chandra A and Chandra S 1995 Phys. Rev. B 52225

Weston J E and Steele B C H 1982 Solid State Ionics 775

Wright P V, Parke J M and Fenton D E 1973 Polymer 14589 